PROC. OF JSCE,

No. 242, OCT. 1975

\title{
STUDIES ON TESTS FOR SPLITTING TENSILE STRENGTH OF CONCRETE
}

\author{
By Atsuhiko MACHIDA*
}

\section{INTRODUCTION}

The splitting tensile strength test method has many merits compared with the direct tensile test method, such as it can be conducted much more easily, the scatterings of the test results are very narrow, and so on. This method, therefore, has been prescribed in many standards as the standard test method for tensile strength of concrete.

It was initially proposed by Tsuneo Akazawa of Japan in 1943 ${ }^{1)}$. He studied experimentally on the method, in which a cylindrical specimen is laid down and the load is directly applied to the specimen without anything between the specimen and bearing plates of a testing machine, and concluded that (i) assuming the elasticity of concrete and the ideal line load the tensile strength can be calculated by eq. (1), (ii) reliable results are obtainable by this method, (iii) testing procedure is very easy, and so on.

$$
\sigma=\frac{2 P}{\pi d l}
$$

where $\sigma=$ tensile strength, $d=$ diameter of specimen, $l=$ length of specimen, $P=$ ultimate load at failure.

Based on the results of many Japanese researchers, such as M. Uchiyama ${ }^{2)}$ and $M . K^{2}$ Kubu $^{3)}$, Akazawa's method was prescribed in JIS (Japanese Industrial Standards) $)^{4}$ as the standard test method for tensile strength of concrete in 1951. In 1949 independent of Akazawa, F. Carneiro and A. Barcellos ${ }^{5)}$ of Brazil proposed another splitting test method to insert strips between a specimen and bearing plates of a testing machine and apply the load through strips. In $1951, \mathrm{~J}$. Vuorinen ${ }^{6)}$ proposed that eq. (2) ought to be used to calculate the tensile strength in the Brazilians' method.

$$
\sigma=\frac{2 P}{\pi d l} \cdot \frac{C}{1+m K}
$$

* Associate Professor, Department of Foundation Engineering, Saitama University where $C=$ theoretical stress coefficient, implying the effect of the shape of cross section of specimen and the effect of the width of strips, $K=$ ratio of the width of strips to the diameter of specimen, $m=$ experimental stress distribution coefficient $(=3.75)$.

Many researchers in the U.S.A.7),8),9) and Europe $^{10), 11), 12), 13)}$ carried out studies on the Brazilians' method in the 1950's and 1960's. The splitting method with strips was prescribed in ASTM ${ }^{14}$ and RILEM ${ }^{15)}$, in 1962 and in 1966, respectively.

As described above, there are two practical ways to test by the splitting method. Each of them has merits and demerits, and superiority or inferiority between them cannot be decided immediately. Some reports ${ }^{8), 9), 10)}$ already published emphasized the necessity of strips but their conclusions were not confirmed by experimental evidence. In this paper, these two practical ways are compared with one another, on the basis of horizontal strain distributions and crack patterns observed along the vertical axis of a specimen and the obtained tensile strengths.

The author was fortunate to receive a Yoshida Subsidy from the Japan Society of Civil Engineers for the investigation reported herein. This paper was critically studied by Prof. M. Kokubu of the University of Tokyo. His helpful comments are also gratefully acknowledged.

\section{EFFECT OF STRIPS ON THE STRAIN AND STRESS DISTRIBUTIONS ALONG THE VERTICAL AXIS OF A SPECIMEN}

In order to clarify the difference of the tensile stress distribution along the vertical axis of a specimen between the test method with strips and without, the calculations were carried out, using the theoretical stress equation (3) of the elastic disk and assuming that the disk is subjected to the diametral compression load which is distributed over an area of its edge. In these 
calculations, number of terms summed up to get one stress was upto 364 .

$$
\begin{aligned}
\sigma_{r}=- & \frac{2 P}{\pi}\left[\alpha+\sum_{n=0}^{\infty}\left(\frac{r}{a}\right)^{2 n}\left(1-\frac{n}{n+1} \frac{r^{2}}{a^{2}}\right)\right. \\
& \times \sin 2(n+1) \alpha \cos 2(n+1) \theta] \\
\sigma_{\theta}=- & \frac{2 P}{\pi}\left[\alpha+\sum_{n=0}^{\infty}\left(\frac{r}{a}\right)^{2 n}\left(-1+\frac{n+2}{n+1} \frac{r^{2}}{a^{2}}\right)\right. \\
& \times \sin 2(n+1) \alpha \cos 2(n+1) \theta] \\
\tau_{r \theta}= & \frac{2 P}{\pi} \sum_{n=0}^{\infty}\left(\frac{r}{a}\right)^{2 n}\left(1-\frac{r^{2}}{a^{2}}\right) \\
& \times \sin 2(n+1) \alpha \cdot \sin 2(n+1) \theta
\end{aligned}
$$

where $a=$ radius of disk,

$$
\alpha=\text { (distribution width of load)/ } 2 a
$$

The calculated tensile stresses indicate clearly that as the width of the load increases, the region of the uniform tensile stress diminishes and the region of the compressive stress near the loaded portion enlarges (see Fig. 1).

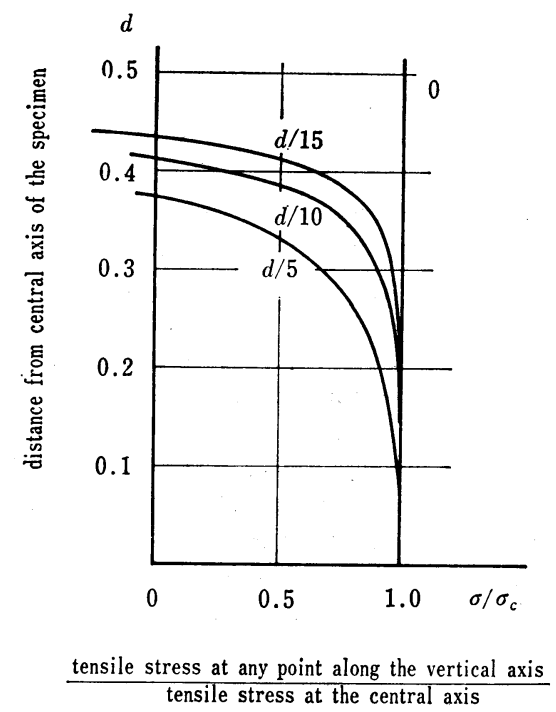

Fig. 1 Calculated Stress Distributions, when Loads of Various Distributing Widths are Applied.

The strain distribution along the vertical axis of a specimen was calculated from this stress distribution, assuming Poisson's ratio of 0.2 and plain strain condition. The result of the calculation is as shown in Fig. 2. As clearly shown in Fig. 2, the strain in the case of the distributing load shows a remarkable difference from that of line load.

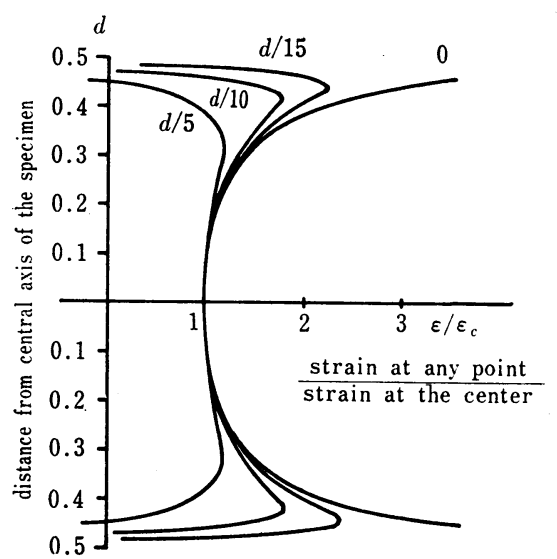

Fig. 2 Calculated Strain Distributions when Loads of Various Distributing Widths are Applied.

In order to compare these results with the actual strain in a concrete specimen, horizontal strains at 17 points along the vertical axis of a specimen were measured using strain gages of 3 . $\mathrm{cm}$ length. The specimens used were cylindrical ones of diameter $30 \mathrm{~cm}$ and height $10 \sim 15 \mathrm{~cm}$, which were made of concrete with the coarse: aggregate of maximum size $12.5 \mathrm{~mm}$. The experiments on the test methods of applying load through strips were carried out in the first place. Strips used were made of $3 \mathrm{~mm}$ thick waterresistant plywood, which is graded in the 1st: class by JAS (Japanese Agricultural Standards),

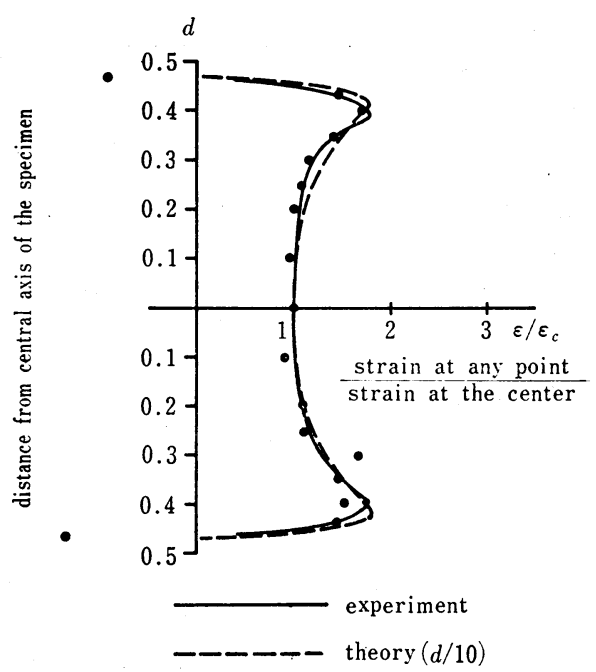

Fig. 3 Experimented Strain Distributions: (d/10 Strip) and Theoretical Distribution. 
and their widths were $d / 10$ and $d / 5$. The ratios of the strains at various points to the central one were calculated. Some examples of these calculations are as shown in Fig. 3 Fig. 5. Average values of these ratios in the range of $20 \% \sim 80 \%$ of ultimate load are shown in the figures, since within this range they were almost constant. The measured strain distributions coincide fairly well with the calculated ones, as clearly shown in Fig. 3 Fig. 5. This fact indicates that the stress distribution along the vertical axis of a

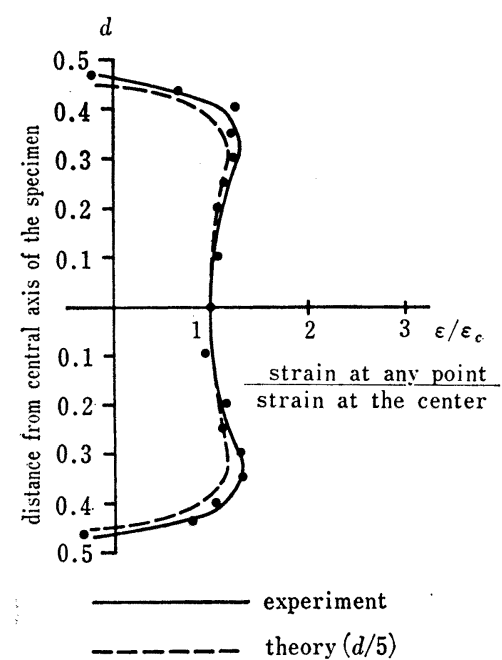

Fig. 4 Experimental Strain Distributions $(d / 5$ strip, thickness $=3 \mathrm{~mm})$ and Theoretical Distribution.

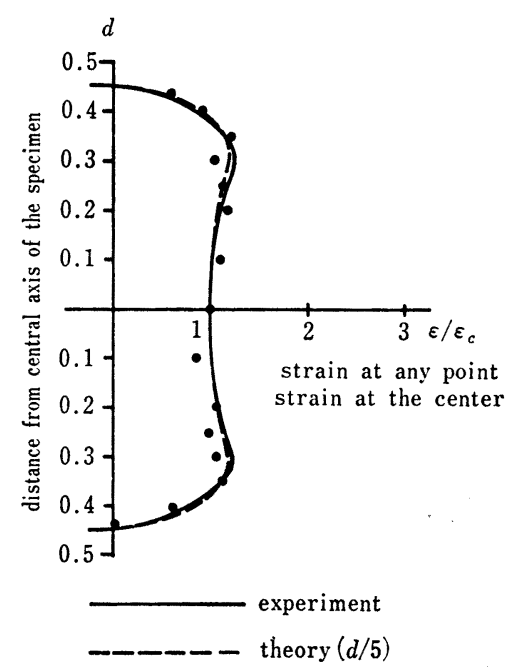

Fig. 5 Experimental Strain Distributions $(d / 5$ strip, thickness $=10 \mathrm{~mm})$ and Theoretical Distribution. specimen in the splitting test with strips of $d / 10$ $\sim d / 5$ width is, at least within the range of $20 \% \sim$ $80 \%$ of ultimate load, nearly equal to the distribution calculated by the elastic theory, which is shown in Fig. 1, when the quality of the strip is suitable. Based on the elastic theory, many researchers have pointed out that eq. (1) may be used for calculation of the tensile strength although the strips are used, because the tensile stress equal to that of the ideal line load arises in the region of three quarters of a specimen. The test results described above suggest this is true. As indicated in Fig. 1, however, it holds good only when the width of the strip is below $d / 10$, and the region of uniform tensile stress is only a half region of a specimen, when the width is $d / 5$. Therefore, use of eq. (1) is questionable in the test with strips, particularly in wide strips. This will be discussed further in 4 .

Above $80 \%$ of the ultimate load, the strain distributions in the specimens loaded through the strips of $d / 5$ were similar to those of Figs. 4 and 5 until slightly before the ultimate load. In the case of $d / 10$ strips, however, the strains increased rapidly in the region from $0.4 d$ to the edge at these loading stages, even though those of $0.4 d$ -0 made no great difference with Fig. 5. This is because the partial crushing at the loaded portion progressed into the position where the strain gage was located. This partial crushing will be discussed in 3 .

The same experiments as above were carried out on the test method of using no strip. In these experiments, the ratios of the strains at

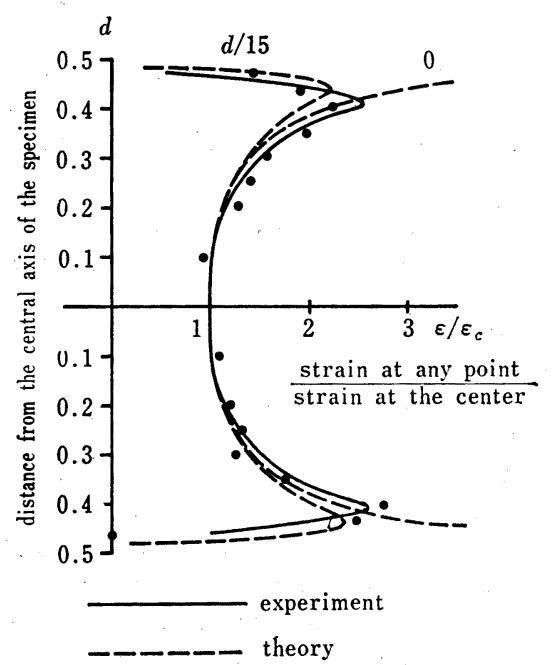

Fig. 6 Experimental Strain Distribution (No Strip) and Theoretical Distribution. 
various points to the central one were also nearly constant in the range of $20 \% \sim 80 \%$ of ultimate load with the exception of the outermost one, and so, one example of those values was shown in Fig. 6. As obviously shown in Fig. 6, the strain distribution coincides rather with the calculated ones of the distributing load of $d / 15$ width than ideal line load. This may depend on the fact that the loaded portion of a specimen is crushed during loading, when the strip is not used. Owing to this fact, the load is not concentrated but distributed into relatively narrow areas, and the strain distribution becomes as if the strips of about $d / 15$ width were used.

Based on the elastic theory, it has been considered that a uniform tensile stress arises along the vertical axis of a specimen when tested by the method of no strip. These results, however, indicate that although in this method, the stress is not uniform but becomes compressive near the loaded portion, similar to that of the distributing load.

In another words, difference of the stress distribution perpendicular to the vertical plane which include the central axis of a specimen is not so great between the method of no strip and with strips as indicated by the elastic theory. However, the region of uniform tensile stress in one method is different from another. As described later, the distributing width of the load in this case may be about $d / 15$, when the cylindrical specimen of diameter of $15 \mathrm{~cm}$ is used and the concrete is of ordinary quality, and so, the range of the uniform tensile stress in the method of no strip, must be wider than in the method with strips of $d / 10$ width.

When the load is below $20 \%$ and above $80 \%$ of the maximum, moreover, the same phenomena were indicated as the case of $d / 10$ strips.

\section{PARTIAL CRUSHING AT THE LOAD- ED PORTIONS OF A SPECIMEN}

In the method of no strip, it is feared that the partial crushing at the loaded portions of a specimen may lead to its whole failure and too low strength may be given. In order to investigate this, the cracks formed in specimens slightly before the failure are observed as follows: the instant a specimen broke down was judged from increasing characteristics of the horizontal strain at the center of the specimen which had been recorded in $X-Y$ recorder, and just at this instant the specimen was unloaded, and the cracks were observed by means of a microscope of magnifying power of $20 X$. The state judged by this method is near enough to failure, since the average maximum load at this instant was $96 \%$ of the ultimate load. Fig. 7 (a) shows all cracks observed by this method which were put upon one another in 12 specimens. It is indicated in Fig. 7 (a) that many short cracks appear near the loaded portions. However, these cracks are limited to these portions and it is hardly recognized that they advance into the central portion of a specimen. To make this more clear, the specimens were loaded again to failure, and all cracks observed at failure were put upon the cracks in Fig. 7 (a), then the cracks which correspond to the ones at failure were selected out of the cracks in Fig. 7 (a). The result is as shown in Fig. 7 (b) and it is recognized that short cracks at the loaded portions correspond rarely to the cracks at failure but cracks at the central portion of the specimen correspond rather well to the cracks at failure.

Accordingly, it is hardly recognized that the short cracks of this kind lead to the whole failure of a specimen. The reason for this may be that

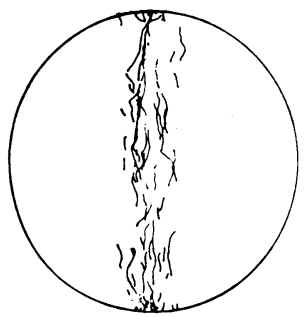

(a) Cracks slightly before failure

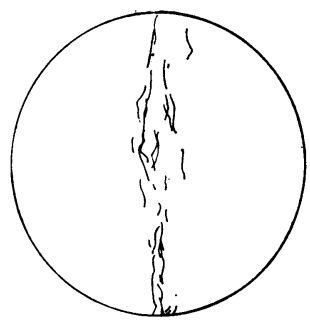

(b) Cracks which coincide with failure plane
Fig. 7 Observed Cracks in Specimens Loaded without Strip.

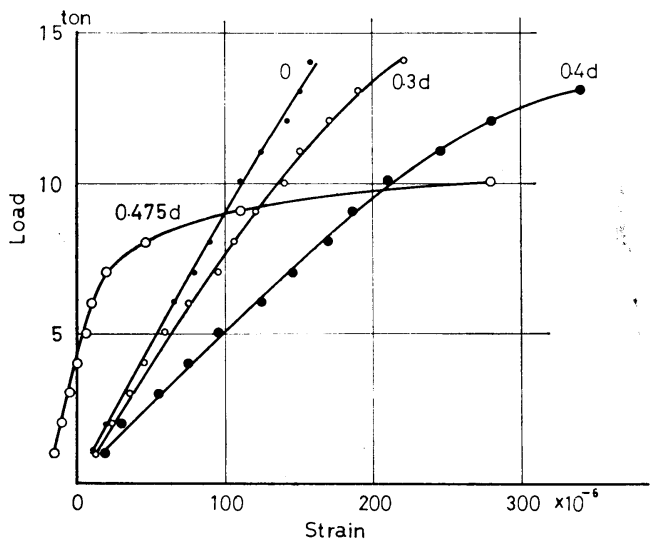

Fig. 8 One Examples of Relations between Load and Strain. 
Table 1 Effects of Test Methods on Test Results.

\begin{tabular}{|c|c|c|c|c|c|c|c|}
\hline $\begin{array}{l}\quad W / C \\
\text { Compressive } \\
\text { Strength }\end{array}$ & Strips & $\begin{array}{l}\quad(1) \\
\text { Average } \\
\text { Tensile } \\
\text { Strength } \\
\left(\mathrm{kg} / \mathrm{cm}^{2}\right)\end{array}$ & $\begin{array}{c}\text { Coefficient } \\
\text { of } \\
\text { Variation } \\
(\%)\end{array}$ & $\begin{array}{l}\text { Strength } \\
\text { Ratio in } \\
\quad(1)\end{array}$ & $\begin{array}{l}\quad(2) \\
\text { Modified } \\
\text { Tensile } \\
\text { Strength } \\
\left(\mathrm{kg} / \mathrm{cm}^{2}\right)\end{array}$ & $\begin{array}{l}\text { Strength } \\
\text { Ratio in } \\
\text { (2) }\end{array}$ & $\begin{array}{c}\text { Number } \\
\text { of } \\
\text { Specimens }\end{array}$ \\
\hline \multirow{5}{*}{$\begin{array}{c}40 \% \\
519 \mathrm{~kg} / \mathrm{cm}^{2}\end{array}$} & none & 34.4 & 5.8 & 1 & 27.4 & 1 & 10 \\
\hline & $d / 10,3 \mathrm{~mm}$ & 35.4 & 7.1 & 1.03 & 25.6 & 0.93 & 7 \\
\hline & $d / 10,10 \mathrm{~mm}$ & 35.1 & 3.2 & 1.02 & 25.4 & 0.93 & 3 \\
\hline & $d / 5,3 \mathrm{~mm}$ & 39.2 & 7.4 & 1.14 & $(22.0)$ & $(0.80)$ & 6 \\
\hline & $d / 5,10 \mathrm{~mm}$ & 39.1 & 3.5 & 1.14 & $(22.0)$ & $(0.80)$ & 6 \\
\hline \multirow{4}{*}{$\begin{array}{c}55 \% \\
360 \mathrm{~kg} / \mathrm{cm}^{2}\end{array}$} & none & 28.6 & 5.3 & 1 & 22.8 & 1 & 5 \\
\hline & $d / 10,3 \mathrm{~mm}$ & 30.1 & 3.8 & 1.08 & 21.8 & 0.96 & 5 \\
\hline & $d / 5,3 \mathrm{~mm}$ & 33.2 & 4.4 & 1.16 & (18.7) & $(0.82)$ & 3 \\
\hline & $d / 5,10 \mathrm{~mm}$ & 33.2 & 6.4 & 1.16 & (18.7) & $(0.82)$ & 3 \\
\hline \multirow{3}{*}{$\begin{array}{c}70 \% \\
215 \mathrm{~kg} / \mathrm{cm}^{2}\end{array}$} & none & 21.5 & 4.3 & 1 & 17.1 & 1 & 5 \\
\hline & $d / 10,3 \mathrm{~mm}$ & 24.5 & 3.4 & 1.14 & 17.7 & (1.04) & 5 \\
\hline & $d / 5,3 \mathrm{~mm}$ & 26.9 & 2.3 & 1.25 & $(15.1)$ & $(0.88)$ & 5 \\
\hline
\end{tabular}

the cracks of this kind do not advance into the inner part of a specimen, which is the region of tensile stress, being limited to the regions of compressive stress at the loaded portions. An example of the movement of the strains measured at the various parts of a specimen is as shown in Fig. 8, and it is indicated in this figure that the cracks of this kind which appear near the loaded portion develop considerably before the failure (about $60 \%$ of the ultimate load in this example) but that these cracks do not produce an influence on the strains farther in than $0.4 d$. This result supports the discussion discribed above and indicates that in the test method of no strip cracks at the loaded portions of a specimen being limited almost always to only this local region, these cracks do not have serious effects on the whole failure of a specimen.

The cracks in a specimen loaded through strips were observed similarly. It was indicated from the results that the cracks arise near the loaded portions although the strips were used. These cracks, however, were limited to that part, similarly as the method without strip and did not change the strains from 0 to $0.4 d$ greatly. Therefore, they do not have serious effects on the whole failure of a specimen.

\section{EFFECT OF THE TEST METHOD ON TENSILE STRENGTH GIVEN}

The splitting tensile strength tests were carried out using two kinds of methods, one of which was the method of no strip and the other with strips, and the tensile strengths by these methods were calculated from the maximum loads indicated by the testing machine using eq. (1), with the results shown in Table 1 . It is indicated in Table 1 that the obtained tensile strengths differ considerably according to the test method. That is to say, the lowest strength is given in the method of no strip, and, higher strength is given as the width of a strip becomes large. For example, the test method with $d / 10$ strips showed $8 \%$ and the method with $d / 516 \%$ larger strength than that of no strip, when the concrete was of $W / C=55 \%$. The results in Table 1 indicate that larger tensile strength is given as the distributing width of the load is enlarged, since in this study the distributing width in the method of no strip is about $d / 15$, as described in 5 .

It has been recognized based on the elastic theory that when the distributing width of the load is less than $d / 10$, (1) may be used to calculate the tensile strength although strips are used as described in 1 . However, the author cannot but consider that it is not suitable to use eq. (1) in the method with the strips of not only over $d / 10$ but also below $d / 10$ since there are obvious differences between the results by the method of no strip, in which the distributing width may be about $d / 15$, and the method with $d / 10$ strips.

In another words, in order to obtain the true tensile strength of concrete, it is necessary to 
modify the result given by eq. (1) considering the distributing width of the load.

Table 1 also indicates that the ratio of the tensile strength obtained by each method differs according to the compressive strength of concrete, i.e., the ratio of test results of $d / 10$ strips to those of no strip is 1.03 in the case of concrete of $W / C=40 \%$, and it becomes 1.08 and 1.14 , in the case of concrete of $W / C=55 \%$ and $70 \%$, respectively. This fact suggests that it is not sufficient for modifying the results by the splitting methods to take into consideration only the distribution width of the load, and that the compressive strength of concrete must, at least, be added to it.

The results of the calculations by eq. (2) are also given in Table 1 . In these calculations, the distribution width of the load was assumed to be $d / 15$ in the method of no strip and $K$ and $C$ obtained by extending the range of the table given by Vuorinen were used in the method of the $d / 5$ strip. As clearly shown in Table 1, the difference in the results calculated by eq. (2) becomes smaller than that of eq. (1) when the compressive strength of concrete is low. On the contrary, when the concrete strength is high, this becomes larger. In eq. (2), the effect of the compressive stress near the loaded portion is taken into consideration in addition to the distribution width of the load. The result shown in Table 1 , however, may indicate that eq. (2) also remains imperfect for the modification of results of splitting tests. One reason why such results were obtained may be the frictional force between a specimen and strips. That is to say, when the strips are used, this friction may restrict splitting of the specimen. This fact was not dealt with in this paper, but is considered to be an important problem to be solved.

There may be no reasonable way to modify the result of the splitting test considering all these conditions and to obtain the true tensile strength, and so, prospective investigation should be given to this problem. At present, it is necessary to presume which method gives the result nearest to the true tensile strength. Within the limits of this experiment, it is considered that the method of no strip gives a result nearest to the true tensile strength, since the partial crushing at the loaded portions of a specimen does not affect the failure of the whole specimen and the distribution width of the load is smallest; as described later, when concrete of ordinary quality is tested.

\section{SCATTERING IN RESULTS OF SPLIT- TING TESTS}

The partial crushing at the loaded portions of a specimen may give one of the reasons why scattering of the results is caused in the splitting test of no strip, because the width of the crushing may be different with each specimen, and accordingly, the distribution width of the load may be different. When the diameter of a specimen, the maximum size of coarse aggregate and the quality of concrete are equal, however, it was indicated by the measurement of the crushed widths in specimens unloaded slightly before failure using steel tape that the width of the crushing is nearly constant (see Table 2). Table 2 also shows that the crushed width slightly diminishes as the compressive strength of concrete becomes larger but that this diminution is very small, i.e., the crushed width changes from $d / 15$ to $d / 17$ when the concrete strength changes largely as from $215 \mathrm{~kg} / \mathrm{cm}^{2}$ to $519 \mathrm{~kg} / \mathrm{cm}^{2}$. The distribution width of the load in the method of no strip, therefore, may be considered to be constant, although the quality of the concrete varies.

Table 2 Crushed Width at Loaded Portion of Specimen Loaded Without Strip.

\begin{tabular}{c|c|c|c}
\hline & $\begin{array}{c}W / C=40 \% \\
\left(519 \mathrm{~kg} / \mathrm{cm}^{2}\right)\end{array}$ & $\begin{array}{c}W / C=55 \% \\
\left(360 \mathrm{~kg} / \mathrm{cm}^{2}\right)\end{array}$ & $\begin{array}{c}W / C=70 \% \\
\left(215 \mathrm{~kg} / \mathrm{cm}^{2}\right)\end{array}$ \\
\hline Top & $0.9 \mathrm{~cm}$ & $1.0 \mathrm{~cm}$ & $1.0 \mathrm{~cm}$ \\
\hline Bottom & $0.9 \mathrm{~cm}$ & $1.0 \mathrm{~cm}$ & $1.0 \mathrm{~cm}$ \\
\hline Average & $\begin{array}{c}0.9 \mathrm{~cm} \\
(=d / 17)\end{array}$ & $\begin{array}{c}1.0 \mathrm{~cm} \\
(=d / 15)\end{array}$ & $\begin{array}{c}1.0 \mathrm{~cm} \\
(=d / 15)\end{array}$ \\
\hline
\end{tabular}

* Slump of concrete was $8 \sim 10 \mathrm{~cm}$.

* * Max. size of coarse aggregate was $25 \mathrm{~mm}$.

In another words, scattering of results due to different widths of crushing in the method of no strip is unnecessary to be over-estimated too much. Moreover, it may be concluded that the distribution width of the load in the method of no strip is narrower than in the methods with strips prescribed in any of the standards, when the concrete is in the range of ordinary quality with coarse aggregate of $25 \mathrm{~mm}$ maximum size and cylindrical specimens of diameter $=15 \mathrm{~cm}$ are used in the test.

In the method with strips, it is more complicated than in the method of no strip to set both a specimen and strips accurately at the center of a testing machine. So the eccentric setting of a 
Table 3 Effect of Eccentricity on Test Results.

\begin{tabular}{c|c|c|c|c|c|c|c|c}
\hline \multirow{2}{*}{$\begin{array}{c}* \\
\text { Eccentricity }\end{array}$} & Specimen & $e_{0}=0$ & \multicolumn{3}{|c|}{$\begin{array}{c}\text { Corresponds to the center of the testing machine } \\
e_{0}=0\end{array}$} & $e_{0}=2.5 \mathrm{~mm}$ & $e_{0}=5 \mathrm{~mm}$ \\
\cline { 2 - 7 } & Strip & $\begin{array}{l}e_{1}=0 \\
e_{2}=0\end{array}$ & $\begin{array}{l}e_{1}=2.5 \mathrm{~mm} \\
e_{2}=0\end{array}$ & $\begin{array}{l}e_{1}=5 \mathrm{~mm} \\
e_{2}=0\end{array}$ & $\begin{array}{l}e_{1}=0 \sim 5 \mathrm{~mm} \\
e_{2}=0\end{array}$ & $\begin{array}{l}e_{1}=2.5 \mathrm{~mm} \\
e_{2}=2.5 \mathrm{~mm}\end{array}$ & $\begin{array}{l}\text { Corresponds to the } \\
\text { center of the specimen } \\
e_{1}=e_{2}=0\end{array}$ \\
\hline \multirow{2}{*}{$\begin{array}{c}\text { Strength } \mathrm{kg} / \mathrm{cm}^{2} \\
\text { (ratio) }\end{array}$} & 29.8 & 29.8 & 29.2 & 29.8 & 29.1 & 29.6 & 28.9 \\
$(1.00)$ & $(1.00)$ & $(0.98)$ & $(1.00)$ & $(0.98)$ & $(0.99)$ & $(0.97)$ \\
\hline
\end{tabular}

* See the figure below

specimen or strips may become the first reason for the scattering in this method. The test results on this matter are as shown in Table 3 and it is indicated that eccentric setting has little effect on the test results, i.e., the maximum eccentricity in these tests was easily observed by the naked eye and although such excessive eccentricity existed, the error was only $3 \%$. The reason why such results were given may be that the rotation of the bearing plate of the testing machine during loading makes the eccentricity small. Therefore, the scattering due to the eccentricity might be wide when a different bearing plate from this test is used. Complicated setting is one of the defect of the method with strips.

The difference in the quality of the strip is considered to be the second reason of the scattering. To investigate this, experiments were carried out using strips $10 \mathrm{~mm}$ thick in addition to those $3 \mathrm{~mm}$ thick. The results are as shown in Table 1 and the difference in the tensile strength between the two kinds of strips could

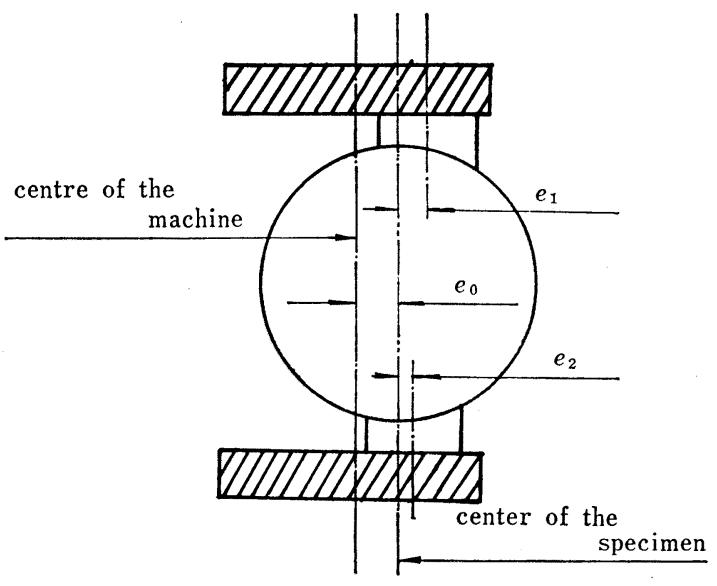

not be observed when the compressive strength of concrete and the width of the strip were not changed. And also, there are no definite differences in the strain distribution and the cracking pattern. From these facts it may be concluded that it is the distribution width of the load mainly

Table 4 Effect of Irregularity of Specimen on Test Results.

\begin{tabular}{|c|c|c|c|c|c|c|c|}
\hline $\begin{array}{r}\text { Irreg } \\
\text { lari }\end{array}$ & none & $\begin{array}{l}\square \\
1 / 6 \text { of one side } \\
\text { is } 0.53 \% \text { smaller }\end{array}$ & $\begin{array}{l}\square \\
1 / 3 \text { of one side } \\
\text { is } 0.53 \% \text { smaller }\end{array}$ & $\begin{array}{l}\square \\
1 / 3 \text { of one side } \\
\text { is } 1.1 \% \text { smaller }\end{array}$ & $\begin{array}{l}1 / 3 \text { of both sides } \\
\text { are } 0.53 \% \text { smaller }\end{array}$ & $\begin{array}{l}1 / 6 \text { of one side } \\
\text { is } 0.53 \% \text { larger }\end{array}$ & $\begin{array}{l}\text { 1/3 of one side } \\
\text { is } 0.53 \% \text { larger }\end{array}$ \\
\hline no & $\begin{array}{l}\mathrm{kg} / \mathrm{cm}^{2} \\
29.7 \\
(100)\end{array}$ & $\begin{array}{l}\mathrm{kg} / \mathrm{cm}^{2} \\
29.9 \\
(101)\end{array}$ & $\begin{array}{l}\mathrm{kg} / \mathrm{cm}^{2} \\
27.7 \\
(93)\end{array}$ & - & $\begin{array}{l}\mathrm{kg} / \mathrm{cm}^{2} \\
24.0 \\
(81)\end{array}$ & $\begin{array}{l}\mathrm{kg} / \mathrm{cm}^{2} \\
24.4 \\
(82)\end{array}$ & - \\
\hline $\begin{array}{l}d / 10 \\
3 \mathrm{~mm}\end{array}$ & $\begin{array}{l}31.1 \\
(100)\end{array}$ & $\begin{array}{l}31.1 \\
(100)\end{array}$ & $\begin{array}{r}30.0 \\
(96)\end{array}$ & $\begin{array}{l}\mathrm{kg} / \mathrm{cm}^{2} \\
28.5 \\
(92)\end{array}$ & $\begin{array}{l}30.3 \\
(97)\end{array}$ & $\begin{array}{c}29.5 \\
(95)\end{array}$ & $\begin{array}{l}26.7^{\mathrm{kg} / \mathrm{cm}^{2}} \\
(86)\end{array}$ \\
\hline $\begin{array}{c}d / 5 \\
10 \mathrm{~mm}\end{array}$ & $\begin{array}{l}33.6 \\
(100)\end{array}$ & $\begin{array}{l}33.4 \\
(99)\end{array}$ & $\begin{array}{l}33.7 \\
(100)\end{array}$ & - & $\begin{array}{l}34.3 \\
(102)\end{array}$ & $\begin{array}{l}34.0 \\
(101)\end{array}$ & - \\
\hline
\end{tabular}


affecting the test results if the quality of concrete is the same, and that the quality of a strip has no serious effects.

In any test method, the irregularity at the surface of a specimen is considered to be the common reason for the scattering. The test results of specimens on the surfaces of which irregularities of several kinds have been formed are as shown in Table 4.

When one third each of the top and bottom of the specimen is indented about $0.08 \mathrm{~mm}$ and loaded without strips, about $18 \%$ lower strength is shown as compared with the case of a specimen of the right shape. This decrease in strength is much larger than when specimens with the same irregularities are loaded through strips. It can be said from this fact that the possibility of occurrence of scattering by irregularities is larger in the method of no strip than in the method with strips. In the method of no strip, however, it is much easier to inspect the existence of the openings between a specimen and bearing plates of a testing machine, as compared with the method with strips. That is to say, inspecting from the side of the testing machine after the specimen is laid on the machine and the bearing plate is touched lightly to it, the openings, in existing, are easily recognized by the naked eye. By this way it is possible to find out such a small opening by which no decrease of the tensile strength is caused, when no strip is used. If the test is carried out taking care to load at the portion of no opening, the scattering due to irregularity can be made negligible in the method of no strip. On the contrary, in the method with strips, it was impossible to find out an opening as large as the maximum ones tested herein, fand it is much more difficult than in the method of no strip to inspect the existence of an opening between a specimen and bearing plates of a testing machine. When the irregularity is excessive and the quality of the strip is not proper, a rather large decrease of the strength is indicated sometimes (see Table 4). Maximum irregularity in this test is such an excessive one that under normal testing conditions it could not occur and the effect of irregularity not so excessive as this on the test result is only several per cent. Accordingly, in the test method with strip, it may be possible by carrying out the test carefully, to keep scattering due to irregularity negligible.

As described above, there are various reasons why scattering in the test results is caused in both methods of splitting tests, the method of no strip and the method with strip. Carrying out the test carefully enough, there must be no great? difference in the degree of the scattering among any test method. This is clearly shown also in Table 1, i.e., the coefficient of variation of the test results in this report being $3 \sim 7 \%$ in any of ! the test methods.

\section{CONCLUSIONS}

The splitting test methods which are prescribed; in the standards of many countries as a standard test method for the tensile strength of concrete are divided into two groups: one is, as in JIS, to lay down a cylindrical specimen between the bearing plates of a testing machine and to load directly, and the other is, as is ASTM and RILEM, to insert strips of plywood or other materials between the bearing plates and a specimen and to load through the strips. These two testing methods are compared on the basis of test results concerning the horizontal strain distributions perpendicular to the vertical plane which contains the central axis of a specimen, the cracking patterns in a specimen slightly before failure, the tensile strengths obtained by these methods and the scatterings in the test results. Within the limits of the tests, the following may be concluded:

(1) In the method of no strip, the comparison of the measured horizontal strain distributions perpendicular to the vertical planes which contain the central axes of the specimens with the theoretical one calculated from the theory of elastic disk showed that the actual strain in a specimen does not coincide with the calculated one of ideal line load but coincides rather well with that of the distribution load for $d / 15$ width. The reason may be that the load is not concentrated but distributed by the partial crushing at the loaded portion of the specimen in this test method. This clearly shows that the stress distribution in a specimen is of the distributed load and not of the concentrated load. Results of the same tests on the method with strips showed that the stress in a specimen is nearly equal to that of the elastic theory, when strips of $d / 10 \sim d / 5$ are used. It is concluded from these results that the main difference in stress distributions between two methods is the range where the uniform tensile stress is working. The distribution width of the load in the method of no strip is $d / 15 \sim$ $d / 17$, when concrete of ordinary quality is tested using cylindrical specimen of diameter $=15 \mathrm{~cm}$, as described in (2). Therefore, in the method of no strip, the range in which the uniform tensile 
stress works is wider than in the method which uses strips of $d / 10$ wide.

(2) Observing the loaded portions of the specimens loaded without strips and unloaded slightly before the failure, the partial crushing can be clearly found out. Results of tests which include microscopic observations of cracking pattern slightly before failure, comparisons of failure characteristics with the cracking pattern and measurements of strain distributions showed that the crushing at loaded portions seldom induce the failure of a specimen at a lower load, being limited small parts. Since at the loaded portions, compressive stress is working, cracks of these parts do not develop into inner range.

Width of this partial crushing is a problem, since this makes the load distributed. Measurements of the widths showed that if the maximum size of coarse aggregate and the dimension of a specimen are same, this is almost constant although the compressive strength of concrete is changed greatly. When concrete with coarse aggregate of maximum size of $25 \mathrm{~mm}$ is tested using a cylindrical specimen of diameter $=15 \mathrm{~cm}$, the width of crushing is $d / 15 \sim d / 17$. It can be concluded from these results that the influence of the partial crushing on test results may be neglected.

From the microscopic observations of the cracking patterns in the specimens loaded through strips, it was indicated that the strips such as prescribed in ASTM or in RILEM do not completely prevent partial crushing. If the strips are used to prevent partial crushing, further investigations on its quality and width are necessary, but the necessity is small because the significance of use of the strips is not so clear, as described above.

(3) The effect of the differences in the quality of strips on the test results is the first problem in the method with strips. The results of the tests showed that the test results is little affected by the quality of strips when the compressive strength of concrete is not changed although the quality of strips changes considerably within such range that they distribute the load over their whole width without breaking during loading.

The second problem is the fact that the eccentrical set of strips or a specimen causes the scattering of the results. The test results have shown that errors owing to this are surprisingly few and although the eccentricity is so great as it can easily be observed by the naked eye, the results differ only by a few per cents. This may be caused, however, by the rotation of the bear- ing plate of the testing machine, and such good results cannot always be expected when the function of a bearing plate is not proper. And also the trouble for making the eccentricity to such a degree that it can be observed by the naked eye is much more complicated than the method of no strip. Accordingly, the difficulties in avoiding any eccentricities should be a defect in the method with strips.

(4) Splitting tests were carried out following the method of no strip, the method with $d / 10$ wide strips and the method with $d / 5$ wide strips, and the tensile strengths were calculated from the maximum load using eq. (1). In these tests different tensile strengths were given according to the testing methods, although the concrete of same compressive strength was tested. In another words, the tensile strength obtained was lowest in the method of no strip, then with $d / 10$ strips and highest in the method with $d / 5$ strips. It has been recognized based on the elastic theory that eq. (1) can be used to calculate the tensile strength even in the method with strips because when distribution width of the load is not so wide, uniform tensile stress of the same magnitude as the ideal line load is produced at the greater part of the specimen, and ASTM and RILEM also prescribe using eq. (1). Considering the test results described above and the fact described in (1) at the same time, however, the use of eq. (1) is not proper when the distributed load is applied. In order to get the true tensile strength of concrete, it is necessary to modify the results obtained by eq. (1). In the modification, it is obvious from the facts described above that the distribution width of the load must be included in the consideration. The above modification, however, is not sufficient and the compressive strength of concrete at least must be added to that because the degree of the difference of the obtained tensile strength differs according to the concrete strength. There has not yet been the reasonable method for modification which takes into account all of the factors like these. This is an important problem to be investigated further.

(5) The irregularity at the side face of the specimen makes openings between the specimen and bearing plate of the testing machine or the strips. The openings cause the scatterings of the results in the method of no strip and the method with strips. In the method of no strip, however, it is easy to inspect the existence of the opening before loading between the specimen and the bearing plate and such a small opening 
that has no effect on the result can easily be found out. When the strips are used, it is diffcult to inspect the existence of the openings. If the opening is excessive and the quality of the strip is not proper, too low results are indicated sometimes. Paying attention to the quality of the strip and the molds, however, it is possible to limit the scatterings of the results to a small enough degree.

(6) Typical methods of splitting test prescribed in standards are the ones of JIS, ASTM and RILEM. When the tests are carried out following these methods, different tensile strengths may be indicated although concrete of the same compressive strength is tested. The JIS method must give the result nearest to the true tensile strength of concrete because in this method the load is nearest to the ideal line load. Following the JIS method, the lowest tensile strength is indicated when the compressive strength is same, as compared with other methods. From the practical point of view, methods which give too high strength are not proper.

There is a defect in the JIS method, that the loaded portion of the specimen is partially crushed during loading, but this defect is not such a one that invalidates the JIS method, as described above. It has been also recognized that the strips prescribed in ASTM or RILEM do not perfectly prevent partial crushing. In another words, use of strips is not only complicating the testing procedure but also less meaning full. Moreover, the attention to be paid minimizing the scatterings of the results is more complicated in the method with strips, although it may be possible to make the coefficient of variation $3 \sim$ $7 \%$ in any method. That is to say, JIS method may be most superior.

\section{REFERENCES}

1) Akazawa, T.: “New test method for evaluating internal stress due to compression of concrete (the splitting tension test) (part 1)," Journal of Japan Society of Civil Engineers, Oct., 1943.

2) Uchiyama, M.: "Tensile strength of concrete and its test method," Transactions of Railway Technical Research Institute, Japanese National Railways, Vol. 3, No. 5, 1944.

3) Kokubu, M.: "Study on the splitting ten- sile strength test of concrete," Proceedings of 1950 JSCE (Japan Society of Civil Engineers) National Meeting.

4) JIS A 1113: "Standard method of test for tensile strength of concrete," 1951 (JIS= Japa. nese Industrial Standards).

5) Carneiro, F. and Barcellos, A.: "Résestance à la Traction des Betons," Broschure des Instituto Nacional de Tecnologia, Rio de Janeiro, 1949.

6) Vuorinen, J.: "Some test on the effect of air-entrainment on the tensile strength and watertightness of concrete by making use of the splitting test method," Transactions, 4 th International Congress on Large Dams, Vol. III, 1951.

7) Thaulow, S.: "Tensile splitting test and high strength concrete test cylinders," Journal of the American Concrete Institute, Jan., 1957.

8) Mitchell, N. B. Jr.: “The indirect tension test for concrete," Materials Research and Standards, Oct., 1961.

9) Rundnic, A., Hunter, A. R. and Holden, F. C.: "An analysis of the diametral-compression test," Materials Research and Standards, April, 1963.

10) Writht, P. J. F.: "Comments on an indirect tensile test on concrete cylinders," Magazine of Concrete Research, July, 1955.

11) Zelger, G.: "Ein neues verfahren zur bestimmung der betonzugfestigkeit," Beton und Stahlbetonbau, July, 1956.

12) Nilson, S.: "The tensile strength of concrete determined by splitting tests on cubes," BULLETIN RILEM N${ }^{\circ} 11$, July, 1956.

13) Nilson, S.: "Tensile strength and compressive strength of concrete on the same cube," BULLETIN RILEM N¹7, Dec., 1962.

14) ASTM designation: C496-62T: “Tentative recomendation of test for splitting tensile strength of molded concrete cylinders," 1962.

15) Commission Essais Des Ciments Et Des Bétons: “Méthode RILEM pour l'échantillonnage, la confection, la conservation et les essais Mécaniques de Béton," BULLETIN RILEM N³0, March, 1966.

16) Kawamoto, C.: “Applied Elasticity," Kyoritsu Shuppan Co. Ltd., 1963.

(Received Feb. 20, 1975) 